\title{
A ESTÉTICA DA PERSUASÃO: AS FORMAS SENSORIAIS DO CRISTIANISMO GLOBAL E DO PENTECOSTALISMO ${ }^{1}$
}

Birgit Meyer ${ }^{2}$

Resumo: O Cristianismo é uma religião mundial devido a sua premissa fundamental, apoiada na experiência de Pentecostes, que marca a substituição de Jesus pelo Espírito Santo. Embora a propagação do Pentecostalismo, com sua ênfase na portabilidade e mobilidade, anuncie uma nova forma de religiosidade, minha intenção não é enquadrar o Pentecostalismo como inteiramente distinto dos outros ramos do Cristianismo. Minha preocupação é retomar a estética para o estudo do Pentecostalismo a fim de desenvolver uma alternativa para as lentes protestantes geralmente usadas para analisá-lo, mas que são cegas à importância das sensações. Mais amplamente, o próprio estudo do Protestantismo sofre por não questionar suas autodescriçóes que tendem a insistir numa postura antiestética e iconoclástica. Isso é profundamente problemático, pois não pode haver uma religião antiestética, não obstante as declaraçóes feitas pela própria perspectiva religiosa. Tais declaraçóes não deveriam permanecer inquestionadas, muito menos serem elevadas a conceitos acadêmicos. Temos aí a oportunidade para teorizarmos não só o Pentecostalismo, mas também o Cristianismo global, no passado e no presente. Isso nos permite contestar, por exemplo, algumas distinçóes simplistas entre o Catolicismo, geralmente entendido como uma "religiosidade mágica" e vinculado a coisas, e o Protestantismo, considerado como um modelo de "religiáo de salvação" que, portanto, rejeita estética, forma e imagens. Embora tais distinçóes possam ser mobilizadas repetidamente em autorepresentaçóes religiosas, enquanto estudiosos precisamos transcender tais afirmaçôes em favor de uma visão mais equilibrada que reconheça a estética - e a materialidade - como sendo uma parte fundamental do Cristianismo e da religião em geral. Usando os conceitos de formas sensoriais e de estética da persuasão, procurei abrir espaço para métodos alternativos de

1 Tradução de Gabriela Neubhaher e Tiago Paraná de Lara, sob orientaçáo e revisão da Prof. ${ }^{a}$ Dr. ${ }^{a}$ Elizamari Becker (UFRGS). Revisão técnica: Emerson Giumbelli, João Rickli e Rodrigo Toniol.

2 Professora do Departamento de Filosofia e Estudos de Religiáo da Universidade de Utrecht, Holanda. Contato: B.Meyer@uu.nl 
teorização e investigação do Cristianismo global, especialmente o Pentecostalismo. Ao chamar a atenção para a importância das sensaçôes e da estética, meu interesse não é celebrar o corpo sensível como um local portátil da verdade e da imediata experiência prazerosa, mas sim mostrar como o corpo e as sensaçóes estão sujeitos a poderosas (e concorrentes) formaçóes político-religiosas. A estética não deveria ser despolitizada ou descartada como inferior ao pensamento racional e a formas de mobilização. Melhor seria considerá-la como central para a formação de modos coletivos e individuais de ser e pertencer. Isso demanda uma análise sofisticada do que a estética torna e não torna sensível, especialmente nos campos da religião e da política, mobilizando o corpo e induzindo sensaçôes. Ao enfatizar as sensações corporais pessoais como índice definitivo para a presença e o poder do Espírito Santo, o Pentecostalismo não só epitomiza a centralidade do corpo como um mensageiro da verdade e da identidade nos dias de hoje. Sua popularidade global também frisa a necessidade de que os estudiosos (e os praticantes) dos campos da religião e da política considerem fortemente o corpo, as sensaçóes e a experiência. A observação de Weber de que o alcance universal e a recuperação da arte e da estética andam juntos - apesar de ele ter visto isso como uma recaída na "religiosidade mágica" - deve ser, portanto, levada a sério: o Cristianismo global exige atenção à estética, entendida no sentido amplo.

Abstract: Christianity is a world religion by virtue of its foundational premise, grounded in the experience of Pentecost, which marked the replacement of Jesus by the Holy Spirit. Although the spread of Pentecostalism with its emphasis on portability and mobility signals a new kind of religiosity, I do not intend here to frame Pentecostalism as entirely distinct from other branches of Christianity. My concern is to recapture aesthetics for the study of Pentecostalism in order to develop an alternative to the Protestant lens, which is often used to analyze Pentecostalism but which is blind to the importance of sensation. More broadly, the study of Protestantism itself suffers by not questioning Protestant self-descriptions that tend to stress an iconoclastic, antiaesthetic stance. This is deeply problematic, as there cannot be an antiaesthetic religion, notwithstanding assertions made from an internal religious perspective. Such assertions should not be taken for granted, let alone elevated to the level of scholarly concepts. This then opens up a space for theorizing both Pentecostalism and global Christianity, past and present. This allows us to challenge, for instance, some simplistic distinctions between 
Catholicism, often understood in terms of "magical religiosity" and as indebted to things, and Protestantism, regarded as a model "salvation religion" and hence as rejecting aesthetics, form, and images. While such distinctions may be mobilized repeatedly in religious self-representations, as scholars we need to transcend such claims in favor of a more balanced view that acknowledges aesthetics - and materiality - as being a fundamental part of Christianity and of religion in general. Using the concepts of the sensational form and the aesthetics of persuasion, I have sought to open up alternative methods for theorizing and exploring global Christianity, especially Pentecostalism. Stressing the importance of sensation and aesthetics, my concern has not been to celebrate the feeling body as a portable site of truth and pleasurable immediate experience but rather to show how the body and sensations are subject to powerful (competing) politico-religious formations. Aesthetics should not be depoliticized or dismissed as inferior to rational thinking and forms of mobilization, but it should be taken as central to the formation of personal and collective modes of being and belonging. This calls for a sophisticated analysis of what aesthetics does and does not render sensible, especially in the fields of religion and politics, by appealing to the body and inducing sensations. Emphasizing personal bodily sensation as the ultimate index for the presence and power of the Holy Spirit, Pentecostalism not only epitomizes the centrality of the body as a harbinger of truth and identity in our time, but its global popularity also emphasizes the necessity for scholars (and practitioners) in the fields of religion and politics to come to terms with the body, sensations, and experience. Weber's observation that universal outreach and the reappraisal of art and aesthetics go together - even though he saw this as fallback into "magical religiosity" - should therefore be taken seriously: global Christianity requires attention to aesthetics, understood in the broad sense.

"A estética nasceu como um discurso do corpo." (Terry Eagleton, A Ideologia da Estética)

Em virtude de sua premissa fundamental do "ide e fazei discípulos de todas as naçóes, batizando-os em nome do Pai, do Filho e do Espírito Santo" (Matheus 28:19-20), o Cristianismo se tornou uma religiáo mundial. Isso traz a questão de qual é a novidade - empírica e conceitual - da noção de "Cristianismo global”. Tal noção destaca um modo novo e distinto através 
do qual o Cristianismo se manifesta no mundo, o que requer atenção especial. Novo, aqui, refere-se tanto aos atuais fenômenos empíricos, modos emergentes de religiosidade que não existiam antes, quanto à inovação teórica e suas repercussões em conceituaçôes passadas e presentes. Portanto, a estrutura do Cristianismo global nos permite não somente compreender transformaçôes efetivas nos dias atuais, mas também desenvolver abordagens alternativas, através das quais nossas noçóes de Cristianismo, como o conhecemos, são alteradas.

Como estudiosos têm observado, as igrejas pentecostais/carismáticas são centrais para a globalização do Cristianismo hoje em dia e, nesse sentido, o Pentecostalismo proporciona, como escreve Ruth Marshall (2009, p. 208), o "arquétipo contemporâneo do Cristianismo como uma 'comunidade sem uma instituição', mas uma comunidade de um novo tipo, própria das formas de conexão difusas, individualizadas e não isomórficas de nosso mundo globalizado". ${ }^{3}$ Buscando ativamente o alcance global, as igrejas pentecostais/ carismáticas funcionam, ou pelo menos almejam funcionar, em redes globais que aproximem cristãos renascidos sob o Espírito Santo, o qual está em toda parte, e não preso a um único local privilegiado. Uma "mensagem transponível” e "práticas portáteis" (Csordas, 2009, p. 4-5) são vitais ao projeto de globalização do Pentecostalismo. O Espírito Santo transpóe todas as barreiras criadas pelos seres humanos e, no entanto, não é uma abstração puramente transcendental e elusiva porque acredita-se que atua por baixo da superfície das aparências, de onde afeta o curso das coisas no mundo material.

A presença ubíqua do Espírito Santo acompanha a compreensão do corpo como um receptáculo do poder divino.É uma presença experiencial que invoca sentimentos. Uma das características mais proeminentes das igrejas pentecostais/carismáticas é o seu apelo sensorial. Com frequência, essas igrejas utilizam músicas e uma oratória poderosa, através das quais os

3 Gostaria de enfatizar que esse ensaio não pretende oferecer uma visão geral acerca da discussão recente a respeito de Pentecostalismo e globalização. Veja também André Droogers (2001, p. 41-61) e Joel Robbins (2004, p. 117-143). 
Cristãos renascidos podem sentir a presença do Espírito Santo $\mathrm{com}$ e $\mathrm{em}$ seus corpos, onde quer que estejam, e agir baseados nesses sentimentos. Sensorial tem aqui tanto o significado do apelo aos sentidos quanto o de espetacular. ${ }^{4}$ Ecoando o desejo atual por sensaçóes e experiências no âmbito religioso, igrejas pentecostais/carismáticas enfatizam a importância de sentir a presença e o poder do Espírito Santo direta e imediatamente. Como a presença corporificada de Deus, é uma fonte de energia portátil. A experiência de tais sensaçôes da presença divina náo acontece inesperadamente, mas requer a existência de uma estética religiosa compartilhada, através da qual o Espírito Santo se torna acessível e perceptível.

A partir da primeira década do século XXI, as igrejas pentecostais/ carismáticas vêm recebendo bastante atenção dos cientistas sociais. Em boa parte da literatura atual, igrejas que ocupam um amplo espectro são vistas através das lentes do Protestantismo. Tal perspectiva, tributária do trabalho de Max Weber, enfatiza as notáveis afinidades eletivas entre o apelo do Pentecostalismo e a difusão do capitalismo, assim como a tendência à divisão em um número cada vez maior de organizaçóes independentes, ou a atitude iconoclasta em relaçáo aos objetos religiosos exacerbada tanto nas igrejas protestantes quanto nas pentecostais/carismáticas, o que denuncia o Catolicismo e as tradiçóes religiosas nativas como a "adoração de ídolos". 5 No entanto, a análise do Pentecostalismo via Protestantismo também cria uma visão reduzida, dificultando um entendimento mais completo dos princípios centrais do Pentecostalismo nos dias atuais, principalmente em

${ }^{4}$ N.E.: No original, "sensational", que tanto pode ser traduzido por sensacional quanto por sensorial. Acompanhando a decisão tomada para os textos a serem publicados no livro "Como as coisas importam: uma abordagem material da religiáo", organizado por Emerson Giumbelli, João Rickli e Rodrigo Toniol, optamos por "sensorial".

5 Veja David Martin (1990); Donald Miller e Tetsunao Yamamori (2007); e Peter L. Berger (trabalho apresentado na centésima conferência em homenagem a "The Protestant Ethic and the Spirit of Capitalism", de Max Weber, Cornell University, Ithaca, New York, October 2004. Disponível em: <www.economyandsociety.org/events/Berger_paper. pdf>. Acesso em: 30 abr. 2008). 
sua “dimensão sensorial” (Meyer, 2007, p. 5-28). Além disso, as lentes protestantes são por si só problemáticas, porque privilegiam uma visão específica do Protestantismo como uma religiāo racional e desencantadora, que transcende o corpo, os sentidos e as manifestaçóes religiosas exteriores. Elas não conseguem dar conta de alguns aspectos cruciais do Protestantismo.

$\mathrm{O}$ meu interesse principal aqui é desenvolver alguns conceitos alternativos que expandem a nossa visão do Pentecostalismo, sobre como ele é visto através das lentes protestantes. Para isso, elaboro a partir de trabalhos que enfatizam a "materialidade" da religiāo - por exemplo, o valor atribuído a corpos, coisas, textos e gestos, de maneira a fazer o divino tangível no imanente. ${ }^{6}$ Primeiramente, eu discuto de maneira crítica a ruptura entre a estética e o Protestantismo e a concomitante rejeição da forma no trabalho inovador de Max Weber. Defendo a necessidade de retomarmos a compreensão da religião como estética, considerada no amplo sentido aristotélico de aisthesis. A partir disso, eu apresento a noção de forma sensorial, de modo a compreender como, de acordo com a experiência e a compreensáo pentecostal, o Espírito Santo atua e a apreciar sua dimensão material. Em terceiro lugar, através da estética da persuasão, eu procuro organizar conceitualmente a interface entre religião, sensação e política para entender as modalidades mais amplas de vínculo e de política do pertencimento, atentando para, como proposto por Jacques Rancière, a "distribuição do sensível” (Rancière, 2006). A partir do Pentecostalismo como um proeminente representante do Cristianismo global, busco não apenas ampliar o nosso entendimento dessa religiosidade sensorial como também traçar novas direções para um estudo mais abrangente do Protestantismo e do Cristianismo em geral, levando em consideração a importância da materialidade. O Cristianismo Global se torna, assim, um novo enquadramento que torna visíveis aspectos por ora desprezados do Protestantismo.

6 Veja, por exemplo, Matthew Engelke (2007); Webb Keane (2007); David Morgan (2005, 2010); Peter Pels (2008, p. 264-283); e Jeremy Stolow (2010). 


\section{RELIGIÃO E ESTÉTICA: ALÉM DE WEBER}

Após mais de cem anos desde a publicação de A Ética Protestante e o Espirito do Capitalismo, o trabalho de Max Weber ainda deixa sua marca no estudo do Protestantismo e, de maneira mais ampla, da religiáo moderna. ${ }^{7}$ De acordo com Weber, o Protestantismo Calvinista, com sua crítica fundamental ao Catolicismo de falsamente atribuir poderes a sacramentos e rituais criados por pessoas - o legado da religiosidade mágica -, promoveu o irreversível "desencantamento" do mundo (Weber, 1920).

Embora o trabalho de Weber tenha se mostrado bastante fértil na pesquisa sobre religiáo - por exemplo, ao apontar a existência de afinidades eletivas entre as esferas da religião e do mercado - ele também possui limitaçóes consideráveis. $\mathrm{O}$ meu argumento central aqui é o de que a dimensão sensorial do Pentecostalismo nos leva a revisitar criticamente a distinção de Weber entre a religiosidade mágica, que atribui poder a atos religiosos, substâncias e rituais, e "religióes de salvaçáo" racionais, que anseiam à experiência pura e imediata que ocorre sem formas e rituais religiosos fixos. Ao fazer isso, pretendo complementar o trabalho de Matthew Engelke, Peter J. Pels e Webb Keane sobre a genealogia da atual compreensão desmaterializada da religião moderna em geral e do Protestantismo em particular. ${ }^{8}$ Enquanto esses autores se concentraram principalmente na abordagem intelectualista de E. B. Tylor $(1958$, p. 8) sobre a religiáo (descrita classicamente como "a crença em seres espirituais") e na linguística estruturalista de Saussure e suas sentenças sobre a arbitrariedade do significante como sendo formativas para as abordagens focadas no significado a partir do estudo da religiáo, foco em Weber como mais um autor fundador cujo trabalho valida as lentes protestantes.

7 Veja, por exemplo, a definição de religião de Clifford Geertz (1973, p. 87-125) que foi paradigmática até há pouco tempo. Para críticas, veja Talal Asad (1993) e Matthew Engelke e Matt Tomlinson (2007).

8 Veja Engelke (2011); Pels (2008); e Keane (2007). 
Embora a distinção entre a religiosidade mágica e as religiōes de salvação esteja presente em A Ética Protestante, essa é mais claramente manifesta em "Rejeições Religiosas do Mundo e Suas Direçôes", ensaio no qual ele compara as atitudes de diferentes tradições religiosas com relação ao mundo ao examiná-las em diversas esferas: econômica, política, estética, erótica e intelectual. Ele propóe um esquema evolucionista no qual as religióes de salvação, culminadas no Protestantismo, estão no nível mais alto. De especial interesse para nós é a seção em que Weber, falando sobre estética, aborda a ligação entre a religiosidade mágica e a arte. ${ }^{9}$

Mencionando dimensôes chave da religião, como artefatos, música, dança, templos etc., Weber enfatiza a síntese inicial entre religiáo e arte, sugerindo que aquela tenha sido o berço desta. Essa síntese possibilitou o desenvolvimento de "estilos" religiosos específicos, o que estabeleceu tradiçôes que carregam certos efeitos religiosos mágicos. Weber entende essa religiosidade estereotipada, cujas formas exteriores estavam voltadas para a eficácia mágica, como "inferiores" à religiosidade das religióes de salvaçáo. Ele a contrasta com uma religiosidade outra, mais elevada, que está apartada da arte: a "ética religiosa da fraternidade" característica das religiôes de salvaçáo. Valorizando os laços religiosos com outros adeptos da religiáo mais do que os laços de sangue, e reverenciando a fé mais do que os prazeres terrenos, essa ética defende uma atitude de distanciamento frente ao mundo em geral, e frente à arte e à estética, em particular:

A arte enquanto suporte de meios mágicos é, para a ética religiosa da fraternidade, assim como para o rigorismo apriorístico, não somente depreciada, como posta diretamente em suspeiçẫo. Por um lado, a sublimação da ética religiosa e a busca pela salvação e, por outro lado, o desdobramento da legalidade da própria arte tendem já em si à conformação de uma relação de tensão progressiva. Toda a religiosidade de redençấo sublimada tem em vista somente o sentido, e não a forma, das coisas e açóes relevantes para a salvaçáo. Ela deprecia a forma como sendo algo muito fortuito, da criatura, desprovido de sentido (Weber, 1970, p. 341).

9 Em Weber (1970, p. 341). 
Weber parece concordar com a depreciação da forma na religiosidade de salvação. Seu desdenho da arte e estética, em contraste com seu foco no significado, também se manifesta em seu ensaio sobre a sociologia da religião, no qual ele sugere um paralelo entre a depreciação religiosa da arte e a depreciação dos elementos mágicos, orgiásticos, extáticos e ritualísticos da religiosidade em favor dos elementos ascéticos e místico-espirituais. ${ }^{10}$ Afirma que as religióes racionais (referindo-se aos movimentos de reforma racional no Judaísmo, ao Cristianismo primitivo e ao Protestantismo ascético) possuíam em comum a condenação da "entrega irrestrita aos característicos valores de produção formal da arte." (Weber, 1970, p. 610). Isso invoca uma forte oposição entre a religiosidade racional e os assuntos terrenos, particularmente nas esferas política, erótica e estética. Aos olhos de Weber, a arte aparece como potencialmente blasfema.

Weber concebe que, na prática, a relaçáo entre arte e religiáo poderia ser restaurada. A síntese renovada aparece quando as religióes pretendem se disseminar: "Quanto mais desejaram ser religióes de massa universalistas e foram, portanto, direcionadas à propaganda emocional e aos apelos de massa, mais sistemáticas se tornaram suas alianças com a arte." sugere aqui uma tensão entre $\mathrm{o}$ alcance universal e a pureza da mensagem. Mesmo da perspectiva de seu próprio modelo, que associa a evolução da religião com sua separação da estética, isso sinaliza um paradoxo: a incompatibilidade entre a propagação universal e a racionalidade religiosa eliminam a habilidade das religiôes de salvação de se tornarem universais. No entanto, como o alcance universal é uma característica central ao Cristianismo e, portanto, ao Protestantismo (como testemunhado nos projetos missionários

${ }^{10}$ Ver Weber (1978, p. 399-634, 608-609).

11 Weber, 1970, p. 343. Esta suspeita a respeito das emoçóes e do apelo estético também se reflete na crítica de Weber de que os modernos renegam julgamentos morais, preferindo julgamentos estéticos (Weber, 1970, p. 324) - uma observação que, conforme Bernice Martin (2006, p. 140) argumenta ao discutir a posição de Weber sobre a estética, prefigura a análise de Jean Baudrillard sobre a sociedade de consumo moderna. 
do século XIX que visavam levar a Palavra aos "pagáos"), pode-se perguntar se a rejeiçáo da arte (e, consequentemente, das coisas, da forma e do estilo) seria possível. Em seguida, retomarei essa tensão e a limitação do modelo de Weber em mais detalhes. ${ }^{12}$

Comecemos com a maneira como o Pentecostalismo contemporâneo desafia o contraste de Weber entre arte/estética e a salvação racional. Em um excelente ensaio, Bernice Martin (2006, p. 141) argumenta:

É obviamente uma religião de salvação, é notória e potentemente uma ética da fraternidade, e assim era de se esperar que assuma uma postura anti-arte. Por outro lado, a caracterização de Weber dos elementos de eficácia "mágica" tradicionalmente mediada através das práticas estéticas que se utilizam de música, gestual e danças também possui uma aplicação persuasiva nas práticas litúrgicas pentecostais e nas performances carismáticas, apesar do papel atribuído por Weber às arquiteturas sagradas e aos artefatos ser menos óbvio no caso Pentecostal. Além disso, o Pentecostalismo, descendente do Metodismo e sua tradição do coração aquecido, claramente se encaixa na caracterização de Weber de uma religiáo universalista direcionada ao apelo às massas, que utiliza mídias estéticas como veículos de "propaganda emocional".

Martin (2006, p. 143) argumenta, em seguida, que o Pentecostalismo “incorpora paradoxos múltiplos” e náo se encaixa perfeitamente no modelo de Weber. Ao discutir a adoção das tecnologias modernas de comunicação pelo Pentecostalismo, seu uso de música e o "estilo de adoração no qual os Dons do Espírito se manifestam através da glossolalia, da profecia, da cura e de outros carismas", Martin afirma que essas práticas "são, indiscutivelmente, modos estéticos da ação humana, já que possuem forma assim como conteúdo e mensagem, dos quais são inextricáveis." (Meyer; Verrips, 2008, p. 22-24). Por esse motivo, a caracterização de Martin do Pentecostalismo como paradoxal por muito pouco não se torna uma crítica mais fundamental ao modelo de Weber, o qual ela mantém mais ou menos intacto. Como esse

${ }^{12}$ Mais detalhes em Birgit Meyer (1999). 
modelo ainda permeia grande parte dos estudos sobre religiáo moderna, tal crítica fundamental é de grande importância. Ela consiste em um ponto de partida indispensável para a reconceituação da estética como intrínseca à religiáo moderna, incluindo náo apenas o Pentecostalismo como também o Protestantismo. Essa empreitada envolve duas questóes centrais e interrelacionadas: o entendimento limitado e a atitude desdenhosa de Weber sobre a estética e seu favorecimento do conteúdo e do significado sobre a forma.

Em relação à primeira questão, é importante relembrar a evolução esboçada por Weber de uma noção ampla da estética ligada à religião em uma noção estrita da estética como situada na esfera específica da arte, que estaria em desacordo com - mas que também poderia ser uma substituta para - a religião. Isso não é característico de Weber apenas, mas é reflexo de entendimentos pós-iluministas de estética. Como resultado da proposta feita por Alexander Baumgarten, filósofo alemão do século XVIII, para estabelecer aesthetica como uma nova ciência do conhecimento sensível, o campo se tornou um tema central dos pensadores Iluministas em diante. Baumgarten defendia um entendimento amplo da estética no sentido de aisthesis, que se refere à capacidade humana de perceber o mundo com seus cinco sentidos e interpretá-lo através dessas percepçóes. ${ }^{13}$ Esse entendimento amplo foi subsequentemente estreitado e a estética acabou sendo um tanto confinada à esfera autônoma da arte e do belo, que se tornou o domínio privilegiado para o discurso sobre o corpo e as sensaçóes na sociedade moderna. Aqui é importante lembrar de Immanuel Kant, porque seu pensamento ainda influencia a maneira como se entende a estética. ${ }^{14}$ Kant identificou a arte como o domínio do julgamento estético. Derivando da própria obra de arte, a apreciação da beleza requer um observador desinteressado e, ainda assim, depende de um

13 Aisthesis designa "nossa capacidade corpórea baseada no poder dado em nossa psique de perceber os objetos no mundo através dos nossos cinco diferentes modos sensoriais... e, ao mesmo tempo, toda uma constelação específica de sensaçôes”. Entendida desta maneira, aisthesis refere-se a "nossa experiência sensória total do mundo e ao nosso conhecimento sensível da mesma” (Meyer; Verrips, 2008, p. 21).

${ }^{14}$ Ver Immanuel Kant (2001). 
sentimento que é objetivo pela virtude de ser compartilhado com outrem. Se consideradas nesse sentido, a arte e a estética se tornam constitutivas do sensus communis aestheticus (ou aesthetischer Gemeinsinn, no original em alemão). ${ }^{15}$

Como Terry Eagleton explica, o entendimento de Kant sobre a estética como a expressão da faculdade humana universal do julgamento, que nos predispóe a sentir o mesmo, independentemente das nossas decisóes e interesses subjetivos, proporcionou um novo paradigma ideológico para a sociedade burguesa ${ }^{16}$. Portanto, a arte invocou um novo tipo de sensus communis distinto da - e potencialmente substitutivo para a - religiáo (como o romantismo enfatizou). A arte e a religião (no sentido de religiosidade mágica) têm em comum a mobilização de sensaçóes e experiências que se localizam no corpo e contrastam com o pensamento racional. Em outras palavras, os discursos modernos sobre a estética e a religião do tipo da religiosidade mágica estão inscritos no dualismo entre corpo e mente. Tais discursos reconhecem a importância dos sentidos, mas ainda os veem como subordinados, se não inferiores, ao pensamento racional. Ao incluir a estética nesse dualismo, perde-se o significado mais amplo de aisthesis que engloba os sentidos $e$ o conhecimento. No entanto, tendo "nascido como o discurso do corpo" (Verrips, 2006, p. 27-33), a estética não pode ser totalmente contida no domínio limitado das artes e no dualismo hierárquico mente-corpo. ${ }^{17}$ Apesar da redução da estética não poder ser simplesmente desfeita por um saudoso retorno a Aristóteles, é importante ressaltar que existe algo excessivo a respeito do corpo, dos sentidos e da experiência que exige uma abordagem mais ampla a fim de desalojar nosso pensamento sobre a estética para alémdessa engessada dualidade.$^{18}$

\footnotetext{
${ }^{15}$ Ver Terry Eagleton (1990, p. 70-110).

16 Ibidem, p. 13.

17 Veja também Brent Plate (2005, p. 24).

${ }^{18}$ Ibidem.
} 
Claramente, essa não foi a preocupação de Weber, o que é sintomático da atitude protestante em relação à religião. ${ }^{19} \mathrm{~A}$ atitude desdenhosa de Weber a respeito da arte e da estética é consonante com as suspeitas protestantes a respeito do uso de formas materiais na comunicação com e sobre Deus. Enquanto a teologia católica reconhece o papel da estética como propiciadora da experiência religiosa (afinal, os sacramentos requerem formas rituais, assim como a presença de Deus se materializa através de imagens - um processo conceituado teologicamente como kenosis), a teologia protestante adota uma posição muito mais cética, que acaba por cegá-la para a sua própria estética. Evidentemente, isso se baseia na conhecida iconoclastia da Reforma, que desafiou o uso de imagens como mediadoras entre pessoas e Deus praticado pelo Catolicismo. ${ }^{20}$ Os iconoclastas lutaram não apenas contra o uso de imagens religiosas, mas também contra as alegaçóes de poder dos clérigos que operavam através das imagens. Não obstante, uma posição radicalmente iconoclasta - que rejeita as imagens e a estética - enfrenta sérios problemas pela falha em reconhecer a natureza do Cristianismo como uma superação da distância entre as pessoas e Deus que requer imagens, ou mesmo que a religiáo requer algum tipo de forma para essa superação.

Retornemos brevemente ao teólogo protestante do começo do século XIX, Friedrich Schleiermacher, conhecido por sua visão romântica da religião como o sentimento de schlecht hinningen Abhängigkeit, que se distinguia do pensamento racional, com o qual podia, portanto, coexistir em um

${ }^{19}$ A oposição entre arte e religião que Weber invoca ainda está presente no pensamento de muitos estudiosos destes campos até hoje. Estudiosos das artes são ávidos em afirmar a autonomia da arte frente à religião; hoje em dia, isso fica evidenciado, por exemplo, na rejeição de alegaçóes de blasfêmia que tenham motivações religiosas. Veja James Elkins e David Morgan (2009).

${ }^{20}$ Enquanto a iconoclastia efetiva foi limitada, sua contínua invocação como uma marca protestante de distinção expóe a postura antimaterial e antiestética que é geralmente esposada pela autorrepresentação protestante de teólogos. Ao mesmo tempo, conforme David Morgan efetivamente mostrou, as imagens têm uma longa história no culto protestante. David Morgan (1998). 
nível mais alto. Embora Schleiermacher (apud Hoenderdaal, 1948, p. 81). considerasse a arte e a religiáo como "duas almas amigas", ele desgostava profundamente do esteticismo, o qual associava com o Catolicismo. O esteticismo era considerado problemático porque substituía a religião verdadeira pela adoração da arte sacra e, portanto, reafirmava o poder da igreja e não o de Deus. Esse ponto de vista repercute em Weber, que foi um grande conhecedor do trabalho de Schleiermacher. Mesmo assim, o desprezo pelo esteticismo não resolveu o problema de que Deus, mesmo quando considerado como além da compreensão humana e, portanto, impossível de ser capturado por formas rituais e imagéticas, precisa estar presente aos fiéis de alguma maneira. Esse problema da presença não surge simplesmente com a proeminência do Pentecostalismo global, mas é intrínseco ao Protestantismo. ${ }^{21}$ Nesse sentido, o fenômeno do Pentecostalismo, no qual a estética é obviamente "um recurso de importância inescapável" (Martin, 2006, p. 146), força a questão persistente sobre a estética e o corpo sensível - e, como explicarei, das formas religiosas - para o centro da discussão.

O teólogo calvinista do século XX, Karl Barth, insistiu que a relação entre os seres humanos e Deus não tem origem no pensamento e nas açóes humanas, e sim no Espírito Santo. Ele rejeita, portanto, teologias que dão espaço à ação humana no engendramento da relação com Deus; segundo ele, isso implicaria na adoraçáo de formas criadas por pessoas que seriam confundidas com Deus. Como der ganz Andere, Deus resiste a qualquer representação humana. Mesmo assim, Barth lutou com a questão sobre como compreender a beleza de Deus: "Se ousamos e devemos dizer que Deus é belo, então com isso, dizemos também como Ele nos ilumina, nos convence e nos persuade. Designamos então não apenas o fato nu e cru de Sua revelação e o poder da mesma, mas também a forma e a figura em que isso é um fato e é poder" (Barth apud Viladesau, 1999, p. 27). A noção de beleza apresentada por Barth corrobora as visóes iluministas sobre a estética como algo relativo à beleza (por exemplo, conforme Kant), mas difere dessas concepçóes ao

${ }^{21}$ Ver Matthew Engelke (2007). 
invocar uma beleza que não se associa a arte, mas a Deus. Como Richard Viladesau explica em Theological Aesthetics, seguindo a tradição protestante, Barth receava cair no esteticismo, temendo que a beleza de Deus "se tornasse a beleza de um ídolo" (Viladesau, 1999). ${ }^{22}$ Há, então, uma tensão em sua teologia entre o reconhecimento da importância da forma - compreendida como aquilo sem o que a beleza náo pode ser transmitida - e o receio de cair na adoração de imagens. ${ }^{23}$

Retornemos ao favorecimento do conteúdo e do significado sobre a forma. Recordemos a afirmação de Weber sobre a religiosidade de salvação como tendo "esvaziado o valor da forma como contingente, como algo da criação, que distrai do significado". Ainda que esse ponto de vista seja consoante com autodescriçóes protestantes, Barth sugere que, mesmo dentro do Protestantismo, essas questóes são mais complicadas. Afinal, Barth reconhece que a forma e a figura são condiçóes necessárias para que a realidade e o poder de Deus se revelem. Ele inclusive sugere que a forma tem um poder de atração característico, através do qual Deus "nos ilumina, nos convence e nos persuade". De fato, as formas religiosas carregam uma estética de persuasão específica, através da qual uma presença divina transcendental deve ser percebida como real e poderosa.

Em resumo, enquanto a abordagem anti-estética do Protestantismo (e por implicação, a minimização da forma, de objetos e de sensaçóes) privilegiada por Weber é consonante com a teologia e as autodescriçóes protestantes sua afirmação sobre a desvalorização da forma nas religiôes de salvação, como é o caso do Protestantismo, deve ser vista com ceticismo. A desvalorização,

${ }^{22}$ Assim como Schleiermacher, de cuja ênfase romântica no sentimento Barth procurou ficar à maior distância possível.

23 É claro, conforme Viladesau também argumenta, estética e forma podem ser acomodadas mais facilmente na Teologia católica, menos desconfiada que formas feitas pelo homem sejam condenadas a se tornarem idolátricas (por exemplo, conforme desenvolve Hans Urs Von Balthasar, colocando a estética "no contexto de uma tradição metafísica platônico-aristotélica da analogia do ser", veja Viladesau, 1999, p. 30). A diferença entre a abordagem católica e a protestante ainda é discernível nas obras teológicas atuais sobre estética.

Debates do NER, Porto Alegre, Ano i9, N. 34, P. I3-45, Ago./DeZ. 20 I 8 
se não a condenação, da forma às custas do significado puro é - como o Pentecostalismo nos lembra - empiricamente errada. O contraste entre as religiôes (do tipo “religiosidade mágica”) que ainda são dependentes da esfera da estética e as religiōes racionais (como o Protestantismo), traz consigo uma compreensão profundamente problemática que moldou não apenas as abordagens atuais sobre o Protestantismo como também, como argumentam Talal Asad (1993) e Webb Keane (2002), o próprio estudo moderno das religióes em geral. A fim de estar presente no mundo, para não mencionar o seu disseminar, a religião requer formas tangíveis e sensacionais. Portanto, deve-se analisar a religião como algo que propicia um tipo específico de estética, contanto que deixemos de lado as suspeitas levantadas pelo modelo de Weber e passemos a fundamentar o nosso entendimento de estética sem limitá-la ao divisor mente-corpo.

Além disso, o desprezo pela forma e pela estética, associado à suposiçáo equivocada de que as religióes de salvação deixam a estética e a forma para trás, oclui a possibilidade de uma crítica da estética e das maneiras como as formas religiosas possuem apelo e persuasão. A visão de Weber de que a estética e a arte são convocadas, por parte das religióes com aspiraçóes universais, para servirem como "propaganda emocional e apelo às massas" confina a estética à esfera dos sentimentos irracionais, que são mobilizados para fins questionáveis. Ao persistir em uma desvalorização intrarreligiosa de formas religiosas e uma rejeição ao que considera adoração de ídolos e blasfêmia, essa visão falha em reconhecer - e criticamente dialogar com a mobilização das formas sensoriais no curso da estética da persuasão.

\section{FORMAS SENSORIAIS}

No estudo da religião, a forma recebe pouquíssima apreciação e atenção. Ela é vista como algo que nos distrai do - ou é meramente um veículo necessário para o-conteúdo. A desconsideração da forma na narrativa de Weber sucede em proveito da apreciação do significado puro e é, basicamente, a gênese de 
uma atitude mais racional que transcende o sentimento. No entanto, abordagens que enfatizam a importância dos sentimentos, seguindo os passos de William James (1920), rebaixam a forma em favor de uma experiência genuína. Essa ênfase na existência de um sentimento religioso primário, individual, autêntico e, nesse sentido, aparentemente sem mediação, é enganosa, pois ela negligencia o papel das organizaçóes e instituiçóes religiosas de proporcionarem formas através das quais tais sentimentos possam ocorrer repetidamente. Apesar de haver grandes diferenças nos pensamentos de Weber e James, ambos concordam em desvalorizar a forma em favor de uma religiosidade que possa existir sem ela, privilegiando o significado (para o primeiro) ou experiência (para o segundo). Ainda, apesar de essa desvalorização da forma poder estar em sintonia com perspectivas internas - certamente no âmbito da teologia Protestante - ela é equivocada no sentido teórico.

Uma das principais preocupaçóes no atual estudo do Protestantismo deveria ser a reapreciação da forma (e de temas afins, como o estilo) como central na estética religiosa. Cunhei, para isso, a noção de forma sensorial. $\mathrm{O}$ conceito é baseado no meu entendimento da religiáo como uma prática de mediação entre os níveis dos humanos e de Deus (ou de algum domínio ou força transcendental). ${ }^{24}$ A noção de mediação propóe a existência de uma distância entre esses níveis que é intermediada pelas formas sensoriais. Não uso forma em oposição ao conteúdo, ao significado, a normas éticas e valores - mas sim como uma condição necessária para expressá-los. Forma também não é um recipiente estático, mas uma modalidade ou dispositivo que permite uma ação repetida - e, nesse sentido, para citar Weber outra vez,"estereotipada”.

Formas sensoriais são modos autorizados de organizar e invocar acesso ao transcendental que moldam o conteúdo (crenças, doutrinas, conjunto de símbolos) e as normas religiosas. Essas formas possuem um papel central na modulaçáo dos praticantes como sujeitos religiosos, envolvendo-os em práticas particulares de culto e padrôes de sentimento. Em consequência, formas sensoriais são parte de uma estética religiosa específica, a qual comanda

${ }^{24}$ Ver Meyer (2006); Meyer e Verrips (2008); e Meyer (2009, p. 1-28). 
um engajamento sensorial dos seres humanos entre si e com o divino, gerando sensibilidades específicas. As religióes atuam através de formas sensoriais historicamente geradas que são distintivas e que induzem padróes repetitivos de sentimento e ação. Essas formas se constituem com o tempo e estão frequentemente sujeitas a contestação e até mesmo ao abandono (como na Reforma Protestante, que substituiu a imagem pelo texto). Elas são, então, um excelente ponto de partida para a observação de processos de transformação religiosa. Mesmo se as religióes mobilizam numerosas formas sensacionais, certas destas alcançam um status especial que sustenta uma identidade religiosa distinta, como os ícones de veneração para os ortodoxos, a leitura da bíblia para os calvinistas, ou o "louvor e adoraçáo" e a glossolalia para os pentecostais.

Desenvolvi a ideia da forma sensorial em minha pesquisa sobre o Pentecostalismo em Gana. Em particular, impressionou-me a maneira específica como o físico e o espiritual estão relacionados na religiosidade pentecostal. Acredita-se que espíritos maus atuam em corpos, alimentos, presentes, ou mercadorias, enquanto o Espírito Santo é visto como uma força que intervém e luta contra os poderes do mal, fazendo com que eles saiam do corpo de uma pessoa possuída, por exemplo. Apesar de a fé em Deus ser frequentemente invocada, ela não é vista como uma atitude interior e espiritual que pode ser guardada para si, mas sim como algo com um sentido mais material. Conhecida como "um olho espiritual e uma mão espiritual", a fé é um dispositivo que garante as bênçãos de Deus aos crentes renascidos. A concretude da fé no poder do Espírito Santo também é impactante em relação à teologia da prosperidade, segundo a qual a riqueza é uma dádiva divina para os leais crentes renascidos. Essa dádiva também se revela na arquitetura das igrejas pentecostais (geralmente auditórios enormes), na presença pentecostal na mídia, ou no estilo de vida e aparência dos pastores (carros de luxo e roupas elegantes). Preocupaçóes pentecostais a respeito da "adoração de ídolos" atribuída ao Catolicismo e tradiçóes religiosas nativas não são apoiadas em uma atitude ascética mais geral que evita o mundo (conforme Weber, se referindo aos primeiros calvinistas, assumiu - erroneamente, segundo 
Campbell). ${ }^{25}$ Há toda uma cultura material pentecostal realmente incrível a demandar uma análise aprofundada. Essa cultura material inclui arquitetura, estilo de vestuário, música, livros, insumo audiovisual, e todos os tipos de sinais de prosperidade que estáo fortemente ligados ao capitalismo de consumo neoliberal.

Esse breve esboço deve bastar para reconhecer que a religiosidade pentecostal não está meramente voltada para uma força desconhecida e transcendental. Essa religiosidade também não é puramente materialista e nem se consome em assuntos mundanos. Há muita preocupação com o estofo do físico - corpos, coisas, imagens - que está, no entanto, sujeito a ser preenchido e operado por forças divinas ou demoníacas. Os seres humanos precisam estar ativos para poderem ser "preenchidos" e sentirem o Espírito Santo, a fim de desenvolver as sensibilidades necessárias a um crente renascido, que sente - ou vê, graças ao dom do discernimento - armadilhas perniciosas que são invisíveis a olho nu. Ser preenchido com o Espírito Santo não é apenas uma questáo de espiritualidade interior contemplativa, mas também de incorporar o poder divino: apenas aqueles preenchidos tornamse invulneráveis a espíritos malignos e qualificados a terem uma vida feliz, saudável e próspera no geral. Isso implica que uma abordagem que somente opóe o material e o espiritual, vendo este o domínio em torno do qual a religiosidade deveria orbitar e aquele como "mera" externalidade, deixa de perceber a razão de ser da fé pentecostal - e do Protestantismo em geral. ${ }^{26}$

Desse modo, considerar as formas sensoriais nos permite apreender com precisão essa confluência do físico e do espiritual (ou transcendental). Estudar o Pentecostalismo através de formas sensoriais oferece uma nova lente, graças a qual os dualismos entre espírito e matéria, forma e conteúdo,

${ }^{25}$ Collin Campbell (1987) criticou a limitação de Weber a um aspecto da religiosidade protestante - sua ética do trabalho, originada do desespero causado pelateologia da predestinação - e sua negligência da esfera de emoçóes que se tornou central na formação da experiência religiosa no Romantismo.

${ }^{26}$ Ver Morgan (1993). 
corpo e alma, são re-visitados sob um entendimento mais amplo da estética. Explorar a religiosidade pentecostal através de formas sensoriais nos permite ir além da abordagem de James da experiência religiosa como primária; em vez disso, podemos nos perguntar como formas religiosas compartilhadas e autorizadas a experimentar o Espírito Santo tornam as experiências pessoais possíveis (e repetíveis). A partir desse ponto de vista, também podemos reconhecer que, em contraste com o que crê Weber, as formas religiosas autorizadas são centrais aos processos de produção de significado e moldagem dos sentidos e corpos dos fiéis. Por conseguinte, uma vez que as formas sensoriais são usadas como uma entrada empírica para o estudo do Pentecostalismo, torna-se possível entender melhor a gênese e o apelo da religiosidade pentecostal.

Exploremos brevemente o valor heurístico da noção de forma sensorial, voltando-nos à experiência do Espírito Santo. Os cultos pentecostais, com sua ênfase no louvor e na adoração ao Espírito Santo através de cançóes eloquentes, oferecem uma forma sensorial que busca envolver os fiéis para que sintam a presença de Deus de uma maneira aparentemente imediata, deixando-os admirados com Seu poder. Observei tais cultos diversas vezes, nos quais os pastores e a congregação cantam e oram pedindo a vinda do Espírito Santo. Instantes depois, as oraçóes ficam cada vez mais altas e muitos começam a falar em línguas. Isso é visto como um sinal de que o Espírito Santo está manifestado. Em certo momento o pastor anuncia o fim da sessão de louvor e adoração e pode convocar o Espírito Santo para curar os doentes, proteger os vulneráveis e expulsar espíritos demoníacos. O desejo de uma conexão direta e portátil com o poder de Deus através do Espírito Santo é o que fez, e ainda faz, com que muitas pessoas migrem para igrejas pentecostais/carismáticas e se tornem renascidas. Embora, em princípio, todos os renascidos sejam aptos e qualificados a o incorporarem, os pastores carismáticos são canais prioritários do poder divino. De fato, disso depende seu carisma e é o que atrai as pessoas para suas igrejas, esperando que elas também sejam "preenchidas” com o Espírito Santo permanentemente e recebam proteção contra o mal, bem como "chuvas de bênçãos divinas". 
É claro que participar de um culto é apenas uma das maneiras pelas quais os cristãos renascidos dedicam seu tempo para louvar e adorar. Cultos virtuais são oferecidos por diversos programas de rádio e televisão, em materiais audiovisuais e na internet. O Pentecostalismo ensina um conjunto de disciplinas religiosas como o estudo da bíblia, jejuns prolongados e oração individual e coletiva nas chamadas células de oração, assim os fiéis podem se "fortalecer no espírito" (Marshall, 2009, p. 210), já que o Espírito Santo não ingressa e mora permanentemente em uma pessoa. Muitos pastores pentecostais escreveram sobre como recebê-lo e mantê-lo através de oraçóes intensas e continuadas. Propagandas dos escritos do famoso pastor pentecostal Chris Oyakhilome, que comanda uma grande igreja chamada Christ Embassy e um império de mídia global, destacam como o Espírito Santo é percebido:

Libere o Poder do Espírito Santo em Você!

Não Caia na Rotina; Aprenda a Colocar sua Fé em Prática!

Você e o Espírito Santo Podem Ser um Time Imbatível que Irá Mudar seu Mundo! (Oyakhilome, 2006).

Esses slogans expressam bem como o Espírito Santo é descrito em uma linguagem mundana que frisa acessibilidade e ação. É uma presença incorporada concreta, poderosa e portátil, e aparentemente há pouco interesse no problema de uma transcendência que foge da ação e do entendimento humanos (conforme Barth o formula). Pelo contrário, cada fiel religioso precisa ser ativo para que o Espírito Santo possa se manifestar em sua vida até que chegue o ponto no qual a pessoa se sinta capturada por ele. Embora alcançar o estado de preenchimento requeira a interiorização de técnicas do corpo ou disciplinas compartilhadas - um processo para se tornar "sujeito a/de Deus", conforme Marshall (2009, p. 128-129) coloca -, a confirmação definitiva da sua presença ocorre através da sensaçáo. De fato, a sensação é o índice pessoal de autenticidade para a presença do Espírito 
Santo ${ }^{27}$, invocada através de formas sensoriais religiosas compartilhadas e de disciplinas concomitantes.

Analisar as práticas de culto individuais e coletivas como formas sensoriais nos permite evidenciar os dispositivos e açôes concretas - a estrutura da repetição autorizada - das quais depende a manifestação do Espírito Santo em crentes renascidos. Apesar de serem sentidas individualmente, as sensaçóes religiosas são socialmente produzidas, e sua repetiçáo estereotipada depende da existência de práticas formalizadas e autorizadas que moldam as sensaçōes religiosas individuais e permitem sua reprodutibilidade. É por isso que me refiro às sensaçóes no duplo sentido de pessoas tendo sensaçóes específicas e da efetiva indução dessas sensaçôes através de formas sensoriais.

\section{ESTÉTICA DA PERSUASÃO}

Entender que a religião oferece uma estética específica, que forma sujeitos religiosos transformando seus sentidos e permitindo modos de incorporação do divino através de formas sensoriais, implica articular sensaçáo e poder. A estética não está apartada das estruturas de poder, mas misturada nelas. Essas formas induzem técnicas do corpo que produzem sensibilidasdes particulares. Tềm um papel fundamental na "distribuiçáo do sensível", ou seja, "o sistema de fatos autoevidentes de percepçáo sensorial que simultaneamente revela a existência de algo comum e as delimitaçóes que definem as respectivas partes e posiçóes nesse mesmo sistema" (Rancière, 2005, p. 12). Entendida como "o sistema de formas a priori que determina aquilo mesmo que se apresenta para a experiência sensorial” (Rancière, 2005, p. 13), para Rancière a estética não é oposta à política, mas sim uma parte inalienável da mesma. As formas a priori não são dadas, como na noção de Kant de sensus communis, mas estão sujeitas ao poder da distribuiçāo, que implica um processo de habilitação e desabilitaçấo das impressóes sensoriais e uma afinação e aperfeiçoamento dos sentidos. Portanto, a distribuição implica um processo político de governo

${ }^{27}$ Veja também R. Marie Griffith (2004). 
da própria possibilidade da sensação. Aqui há uma grande diferença com as abordagens fenomenológicas, que tendem a negligenciar que a sensação, longe de ser imediata, está sujeita a processos sociais de formação. ${ }^{28}$

Embora Rancière admita que a estética possa ser mobilizada por políticas irracionais e demagógicas (o que Walter Benjamim chama de "estetização da política”), ele insiste que seria equivocado reduzir a estética a este uso negativo. A estética também pode ser um espaço de potencialização e criação, situado "do lado da invenção de formas sensíveis e estruturas materiais próprias de uma vida futura" (Rancière, 2005, p. 29). e, assim, um recurso para uma crítica da política dominante. ${ }^{29}$ Já que humanos são seres cientes, estética e politicamente constituem "ordens específicas de visibilidade e sentido através das quais a divisão política em papéis atribuídos e partes definidas se manifesta" (Hinderliter, 2009, p. 1).

Apesar de Rancière e outros inspirados por seu trabalho pouco se interessarem por religião, a conexão entre política e estética interpela meu projeto de teorização sobre o Pentecostalismo contemporâneo. Recapturar a estética para o estudo do Pentecostalismo e da religião em geral abrirá um novo espaço para se pensar sobre religião, política e sensaçóes. As ideias de Rancière são importantes porque removem a estética e os sentidos de um isolamento despolitizado dentro do qual eles foram colocados por pensadores iluministas e por evidenciarem o papel dos sentidos e das sensibilidades na

${ }^{28}$ Ao mesmo tempo, a visão de Merleau-Ponty de que "o sensível... não é nada mais do que uma certa maneira de estar no mundo... de modo que a sensação é literalmente uma forma de comunhão" (citado em Morgan, 2010a, que acrescenta que Merleau-Ponty "fez alusão explícita ao sacramento cristão da eucaristia") é provocadora ao sugerir uma conexão entre sensação e comunhão.

${ }^{29}$ Veja também Claire Colebrook (2008, p. 107-120) acerca da concepção similar de Agamben sobre estética. Exatamente porque é importante, conforme frisei anteriormente, desenvolvermos uma crítica da estética, seria equivocado rejeitarmos a estética como um todo, seja em conjunção com a religião (delineado na seção 1), seja com a política. É altamente problemático ceder o campo do corpo e da estética para o populismo de direita. Veja também Peter Geschiere (2009). 
organização do que chamo de formaçóes estéticas ou, de acordo com Beth Hinderliter, "comunidades de sentido" (Hinderliter et al., 2009; Meyer, 2009). Assim, os sentidos mesmos são modulados e sintonizados no contexto de regimes político-religiosos, oferecendo uma experiência particular do mundo que envolve conexôes horizontais entre pessoas no nível da comunidade, bem como conexôes verticais com alguma força maior. ${ }^{30}$ Longe de estar confinada em um mero encontro primário e pessoal, a estética religiosa autoriza uma distribuição específica do sensível que propicia a experiência religiosa, porém exclui - ou até mesmo anestesia - outra possibilidades ${ }^{31}$. Um foco na ênfase autorizada de certas sensações e na exclusão de outras a distribuição de "sensíveis" alternativos em um campo mais amplo - seria, portanto, um ponto de partida fértil para uma crítica mais sofisticada da estética ( $\mathrm{e}$, consequentemente, da religião e da política) que vai além da mera e simples rejeição ou sublimação.

É importante investigar como a distribuição pentecostal do sensível se relaciona - sobrepondo-se, ampliando, distanciando-se, desafiando e contradizendo - com distribuiçôes alternativas, como aquelas lançadas pelo Estado-nação. De acordo com Rancière, ao investigar isso, seria um erro reiterar distinçôes convencionais entre religião e política, já que ambas possuem estéticas - "nascidas do discurso do corpo", citando Eagleton (1990, p. 13) mais uma vez - como um ponto em comum. Por exemplo, no início das eleiçóes de 2008 em Gana, havia uma considerável ressonância entre a maneira com que as igrejas pentecostais/carismáticas definiam a nação como um espaço de "batalha espiritual” e as estratégias retóricas de partidos políticos rivais que absorveram parte do discurso pentecostal, referindo-se à política

${ }^{30}$ Nesse aspecto, não posso fazer qualquer incursão na recente literatura sobre teologias políticas que surgiu em parte como reação à incapacidade da teoria da secularização em explicar a presença e o apelo públicos da religião na atualidade. Embora a aproximação entre política e religião em um mesmo escopo seja de vital importância, o que me parece faltar nessa literatura é uma maior preocupação com as sensaçôes - e um entendimento mais amplo em relação à estética.

${ }^{31}$ Veja também Susan Buck-Morss (1992, p. 3-41); e Jonathan Crary (2000). 
em termos de forças espirituais e celebrando vigilância e pacificidade como características primordiais dos cidadãos, transformados preferencialmente em cristãos pentecostais. O presidente ganês John Atta Mills sublinha que foi eleito por Deus e declara almejar que Gana se torne um grande campo de oração. ${ }^{32}$ Isso aponta para uma teologia política emergente fundada no Espírito Santo. Entretanto, conforme Ruth Marshall (2009, cap. 6) argumenta a respeito da Nigéria, essa teologia política é intrinsecamente instável, pois a importância central atribuída à experiência espiritual pessoal tende a ser um contraponto à criação de formas estáveis de soberania e comunidade.

Como o apelo das formas sensoriais do pentecostalismo, que governam uma distribuição do sensível específica pode ser explorado? É aqui que a noção da estética da persuasão se encaixa. A estética é parte da "religião vivida” no nível de experiências cotidianas, proporcionando formas sensoriais que persuadem repetidamente as pessoas sobre a verdade e realidade de suas sensaçôes. Deve-se notar que persuasão não pressupóe um sujeito "livre" antes de ser persuadido. Em vez disso, uma estética da persuasão opera dentro de estruturas religiosas de repetição. A maioria das pessoas interpeladas por formas sensoriais já são constituídas como sujeitos religiosos específicos com certos desejos e dúvidas. Assim, a estética da persuasão é intrínseca às formas sensoriais, cujo poder convence os religiosos da veracidade da conexáo entre eles e Deus (ou o transcendental). Em suma, a estética da persuasão é responsável pelos "efeitos da verdade" da religiāo - por exemplo, ao autorizar o corpo a ser o mensageiro da verdade e autenticidade definitivas. ${ }^{33}$

A persuasão é algo baseado nas visóes clássicas da retórica, a qual é analisada como relacional (pois a retórica não é apenas enunciada, mas implica uma conexão entre os emissores e os receptores) e como implicando a coexistência

32 Em ASAMOAH-GYADU, J. Kwabena. Saints, Ancestors, and Charismatics in African Politics: Media and Religion in Ghana's 2008 Democratic Elections. Trabalho apresentado na palestra Sensations: Religious Mediations and the Formation of Identities, Accra, Ghana, 15-18 ago. 2009.

${ }^{33}$ Ver Mattijs van de Port (2006, p. 444-462). 
do conteúdo e das emoçóes, ao passo que o estilo articula o 'quể e o 'como'. ${ }^{34}$ Isso pode ser produtivamente conectado ao entendimento de Aristóteles dos humanos como seres que percebem o mundo através da aesthesis. Não se restringindo à apresentação única do conhecimento puro, a retórica pressupóe o uso efetivo de estilos particulares que apelam para os sentidos e invocam emoçóes, fazendo, assim, o trabalho da persuasão. A retórica também pode ser expandida a modos mais amplos de expressão do que a oratória, incluindo todos os tipos de formas sensoriais que buscam persuadir.

Se a religião refere-se à conexão entre seres humanos e o divino, para que esta seja experimentada como genuína, as formas sensoriais devem ser persuasivas. Até Barth, desconfiado da estetização, reconheceu que Deus "persuade" os seres humanos por meio de "forma e figura" (Barth citado em Viladesau, 1999, p. 27). A importância de formas sensoriais diversas deveria ser óbvia no estudo do Pentecostalismo, com sua rica cultura material e modos experienciais de adoração (ser preenchido pelo Espírito Santo). Quando as formas sensoriais são vistas como indispensáveis para evocar e manter a experiência religiosa, fica claro que os estilos que são parte dessas formas precisam estar no centro das atençóes.

Uma vinheta pode ilustrar como a persuasão figura uma qualidade específica das formas sensoriais. Em agosto de 2009, fui a um culto na Lighthouse Chapel, uma grande denominação pentecostal, em Accra (capital de Gana). Essa denominação possui uma igreja moderna excepcionalmente grande (feita no estilo da Universidade Nacional). Evocando a grandeza das catedrais católicas, é uma forma sensorial com sua própria estética da persuasão. $\mathrm{O}$ edifício bem mantido e com diversas fileiras de assentos - o maior da cidade -, o palco enorme onde o pastor e os cantores atuam e o equipamento audiovisual de última geração são provas do sucesso do Pentecostalismo, encantando os visitantes. No culto em que estive, o pastor pregou sobre o problema de como sentir o Espírito Santo, o que comparou - com um pouco de ironia à experiência da ausência de sensaçáo (erótica) no casamento: "Ainda existe desejo?" Claramente, a necessidade de cada um dos

${ }^{34}$ Limitações de espaço não me permitem ir além na retórica aristotélica, ver Aristóteles (1926). 
fiéis de sentirem e serem tocados pelo Espírito Santo foi frisada. Enfatizando a importância de uma pregação poderosa, o pastor perguntou repetidamente, "Eu estou pregando?", sendo respondido com, "Sim, você está pregando". Com isso se reconhecia que ele não estava pregando de forma artificial, mas sim verdadeiramente reproduzindo a palavra de Deus.

Esse exemplo afirma, mais uma vez, a importância do sentir e do elevar a sensibilidade ao divino. O que também está em jogo é a habilidade do pastor de invocar a presença divina de uma forma reconhecida e persuasiva. $\mathrm{O}$ consentimento exigido dos participantes em reconhecer os poderes do pastor aponta para uma estética da persuasão direcionada a fazer com que a presença do Espírito Santo seja sentida. Esse exemplo ainda nos mostra que a estética da persuasão é uma parte inalienável da religião em geral, e é parte de religióes com grande expansão e alcance como o Pentecostalismo e seu projeto de globalizaçáo. Aqui a estética da persuasão é usada para afirmar a conexão entre os seres humanos e Deus, ancorando as sensaçóes em uma cosmologia plausível.

As formas sensoriais, ao fazerem parte de uma distribuição pentecostal do sensível, induzem uma estética da persuasão que afirma a visão de mundo pentecostal frente à dúvida e ao ceticismo inevitáveis em razão de infortúnios, doenças e pobreza. Mesmo se o índice pessoal de autenticidade para a presença do Espírito Santo está na sensação pessoal, seria errado considerar o Pentecostalismo como puramente individualista. A conexão pessoal com o Espírito Santo oferece uma mobilidade individual, mas também reforça o sentimento de pertencer a uma grande, e até mesmo global, comunidade renascida de crentes. Seguramente esta é uma comunidade de um novo tipo, diferente das estruturas congregacionais ordenadas que caracterizam as igrejas históricas de missão. Porém não deixa de conectar os religiosos por meio de formas sensoriais compartilhadas que geram sentimentos de efervescência - evocando a análise de Émile Durkheim acerca dos efeitos da participação em rituais religiosos. ${ }^{35}$ A estética da persuasão pentecostal

${ }^{35}$ Ver Meyer (2009). 
é, por conseguinte, mobilizada para converter novas pessoas - através da divulgação de milagres e de outros eventos espetaculares de massa, por exemplo. Nesse sentido, opera no interior de políticas de pertencimento mais amplas, caracterizadas tanto por pontos de divergência, quanto por pontos comuns no tocante às definiçôes do sensível e aos modos de apelo sensorial.

\section{AGRADECIMENTOS}

Gostaria de agradecer a Matthew Engelke e Joel Robbins por me convidarem a fazer parte desse empolgante projeto de teorizar o Cristianismo global, o que me permitiu reunir várias linhas do meu trabalho recente. Estou muito agradecida a eles, assim como a Michael Hardt, David Morgan, Mattijs van de Port e Jojada Verrips pelos comentários construtivos, críticos e cuidadosos em versôes anteriores deste ensaio, e a Marry Kooy por sua assistência em questões práticas.

\section{REFERENCIAS}

ARISTOTLE. “Art” of Rhetoric. Translated by G. H. Freese. London: Heinemann, 1926. (Loeb Classical Library, 193).

ASAD, Talal. Genealogies of Religion: Discipline and Reasons of Power in Christianity and Islam. London: Johns Hopkins University Press, 1993.

ASAMOAH-GYADU, J. Kwabena. Saints, Ancestors, and Charismatics in African Politics: Media and Religion in Ghana's 2008 Democratic Elections. Trabalho apresentado na palestra Sensations: Religious Mediations and the Formation of Identities, Accra, Ghana, 15-18 ago. 2009.

BENJAMIN, Walter. Capitalism as Religion. In: MANDIETA, Eduardo (Org.). The Frankfurt School on Religion: Key Writings by the Major Thinkers. New York: Routledge, 2005. 
BUCK-MORSS, Susan. Aesthetics and Anaesthetics: Walter Benjamin's Artwork Essay Reconsidered. October, v. 62, p. 3-41, 1992.

CAMPBELL, Collin. The Romantic Ethic and the Spirit of Modern Consumerism. Oxford: Blackwell, 1987.

COLEBROOK, Claire. Agamben: Aesthetics, Potentiality, and Life. South Atlantic Quarterly, Durham, NC, v. 107, n. 1, p. 107-120, 2008.

CRARY, Jonathan. Suspensions of Perception: Attention, Spectacle, and Modern Culture. Boston: MIT Press, 2000.

CSORDAS, Thomas. Asymptote of the Ineffable: Embodiment, Alterity, and the Theory of Religion. Current Anthropology, Chicago, v. 45, n. 2, p. 163-184, 2004. [Tradução: CSORDAS, Thomas. Assímptota do Inefável: Corporeidade, Alteridade e Teoria da Religião. Debates do NER, Porto Alegre, v. 1 , n. 29, p. 15-60, 2016.]

. Introduction: Modalities of Transnational Transcendence. Anthropological Theory, v.7, n. 3, p. 259-272, 2007.

. Transnational Transcendence: Essays on Religion and Globalization. Berkeley: University of California Press, 2009.

DROOGERS, André. Globalisation and Pentecostal Success. In: CORTEN, André; MARSHALL-FRATANI, Ruth (Ed.). Between Babel and Pentecost: Transnational Pentecostalism in Latin America and Africa. Bloomington: Indiana University Press, 2001. p. 41-61.

EAGLETON, Terry. The Ideology of the Aesthetic. Oxford: Blackwell, 1990. ELKINS, James; MORGAN, David (Ed.). Re-enchantment. London: Routledge, 2009. (The Art Seminar, 7).

ENGELKE, Matthew. A Problem of Presence: Beyond Scripture in an African Church. Berkeley: University of California Press, 2007.

. Material Religion. In: ORSI, Robert (Ed.). The Cambridge Companion to Religious Studies. Cambridge: Cambridge University Press, 2011. 
ENGELKE, Matthew; TOMLINSON, Matt (Ed.). The Limits of Meaning: Case Studies in the Anthropology of Christianity. New York: Berghahn Books, 2007.

GEERTZ, Clifford. Religião como um sistema cultural. In: . $A$ Interpretação das Culturas. Rio de Janeiro: LTC Editora, 1989. . Religion as a Cultural System. In: . The Interpretation of Cultures: Selected Essays. New York: Basic Books, 1973.

GESCHIERE, Peter. The Perils of Belonging: Autochthony, Citizenship, and Exclusion in Africa and Europe. Chicago: University of Chicago Press, 2009. GRIFFITH, Marie. Born Again Bodies: Flesh and Spirit in American Christianity. Berkeley: University of California Press, 2004.

HINDERLITER, Beth et al. (Ed.). Communities of Sense: Rethinking Aesthetics and Politics. Durham, NC: Duke University Press, 2009.

HOENDERDAAL, Gerrit Jan. Religieuze existentie en aesthetische aanschouwing: een studie over het misverstand omtrent het aesthetische element in Schleiermachers wezensbepaling der religie. Arnhem: Van Loghum Slaterus, 1948.

JAMES, William. The Varieties of Religious Experience [1920]. Harmondsworth: Penguin, 1998.

KANT, Immanuel. Crítica da Faculdade de Julgar. Petrópolis: Editora Vozes; Bragança Paulista: Editora Universitária São Francisco, 2017.

. Kritik der Urteilskraft. Hamburg: Felix Meiner, 2001.

KEANE, Webb. Sincerity, "Modernity", and the Protestants. Cultural Anthropology, v. 17, n. 1, p. 65-92, Feb. 2002.

. Christian Moderns: Freedom \& Fetish in the Mission Encounter. Berkeley: University of California Press, 2007.

MARSHALL, Ruth. Political Spiritualities: the Pentecostal Revolution in Nigeria. Chicago: University of Chicago Press, 2009. 
MARTIN, Bernice. The Aesthetics of Latin American Pentecostalism: The Sociology of Religion and the Problem of Taste. In: ARWECK, E.; KEENAN, W. J. F. (Org.). Materializing Religion: Expression, Performance and Ritual. Farnham: Ashgate Publishing, 2006.

MARTIN, David. Tongues of Fire: the Explosion of Protestantism in Latin America. Oxford: Blackwell, 1990

MEYER, Birgit (Org.). Aesthetic Formations: Media, Religion, and the Senses. Basingstoke: Palgrave Macmillan, 2009a.

. From Imagined Communities to Aesthetic Formations: Religious Mediations, Sensational Forms, and Styles of Binding. In: (Org.). Aesthetic Formations: Media, Religion, and the Senses. Basingstoke: Palgrave Macmillan, 2009b.

. Pentecostal and Neo-liberal Capitalism: Faith, Prosperity and Vision in African Pentecostal-Charismatic Churches. Journal for the Study of Religion, Pretoria, v. 20, n. 2, p. 5-28, 2007.

. Religious Sensations: Why Media, Aesthetics and Power Matter in the Study of Contemporary Religion. Inaugural lecture, VU University, Amsterdam, October 6, 2006.

. Translating the Devil: Religion and Modernity among the Ewe in Ghana. Edinburgh: Edinburgh University Press, 1999.

MEYER, Birgit; VERRIPS, Jojada. Aesthetics. In: MORGAN, David (Org.). Key Words in Religion, Media and Culture. Basingstoke: Routledge, 2008.

MILLER, Donald; YAMAMORI, Tetsunao. Global Pentecostalism: The New Face of Christian Social Engagement. Berkeley: University of California Press, 2007. MORGAN, David. Imaging Protestant Piety: the Icons of Warner Sallman. Religion and American Culture: A Journal of Interpretation, v. 3, n. 1, p. 29-47, 1993. 
(Org.). Religion and Material Culture: The Matter of Belief. New York: Routledge, 2010a.

. Introduction: the Matter of Belief. In: (Org.). Religion and Material Culture: the Matter of Belief. New York: Routledge, 2010b. . The Sacred Gaze: Religious Visual Culture in Theory and Practice. Berkeley; Los Angeles: University of California Press, 2005.

. Visual Piety: a History and Theory of Popular Religious Images. Berkeley; Los Angeles: University of California Press, 1998.

OYAKHILOME, Chris. The Seven Spirits of God: Divine Secrets to the Miraculous. Chelmsford: LoveWorld Publications, 2006.

PELS, Peter. The Modern Fear of Matter: Reflections on the Protestantism of Victorian Science. Material Religion, v. 4, n. 3, p. 264-283, 2008.

PLATE, S. Brent. Blasphemy: Art that Offends. London: Black Dog Publishing, 2006.

. Introduction: Filmmaking, Mythmaking, Culture Making. In: (Org.). Representing Religion in World Cinema: Filmmaking, Mythmaking, Culture Making. New York: Palgrave, 2003.

. Walter Benjamin, Religion, and Aesthetics. London: Routledge, 2005.

RANCIÈRE, Jacques. A partilha do sensivel: estética e política. São Paulo: Editora 34, 2005.

. The Politics of Aesthetics: the Distribution of the Sensible. Translated by Gabriel Rockhill. London: Continuum, 2006.

ROBBINS, Joel. Becoming Sinners: Christianity and Moral Torment in Papua New Guinea Society. Berkeley: University of California Press, 2004. STOLOW, Jeremy. Orthodox by Design. Berkeley: Stanford University Press, 2010. TAYLOR, Charles. Sources of the Self: the Making of the Modern Identity. Cambridge: Harvard University Press, 1989. 
TYLOR, Edward B. Primitive Culture. New York: Brentano's, 1924. . Primitive Culture: vol. 2 - Religion in Primitive Culture. New York: Harper and Row, 1958.

VAN DE PORT, Mattijs. Visualizing the Sacred: Video Technology, "Televisual" Style, and the Religious Imagination in Bahian Candomblé. American Ethnologist, v. 33, n. 3, p. 444-461, 2006.

VERRIPS, Jojada. Aisthesis and An-aesthesia. Ethnologia Europaea, v. 35, n. 1/2, p. 27-33, 2006.

VILADESAU, Richard. Theological Aesthetics: God in Imagination, Beauty and Art. New York: Oxford University Press, 1999.

WEBER, Max. A Ética Protestante e o Espírito do Capitalismo. São Paulo: Companhia das Letras, 2004.

. Economy and Society: an Outline of Interpretive Sociology. Edited by Guenther Roth e Claus Wittich. Berkeley: University of California Press, 1978.

. The Protestant Ethic and the Spirit of Capitalism. Translated and edited by Talcott Parsons. New York: Charles Scribner's Sons, 1920.

. Religious Rejections of the World and their Directions. In: GERTH, Hans Heinrich; MILLS, Charles Wright (Org.). From Max Weber: Essays in Sociology. London: Routledge; Kegan Paul, 1970. [Edição brasileira: WEBER, Max. Rejeiçôes Religiosas do Mundo e suas Direçôes. In: GERTH, Hans Heinrich; MILLS, Charles Wright (Org.). Ensaios de Sociologia. Rio de Janeiro: Ed. Guanabara, 1982.]

Recebido em: 02/02/2018

Aprovado em: 03/02/2018 
COMENTÁRIOS 